\title{
A POÉTICA DE ARNALDO ANTUNES NA CULTURA DA CONVERGÊNCIA
}

Isa Marques Oliveira*

RESUMO: O artigo propõe uma análise da poética de Arnaldo Antunes no contexto da Cultura da Convergência. Busca-se compreender, portanto, as dimensões signícas-icônicas dos poemas de Antunes, notadamente, percebe-se que as mídias no processo de convergência fortaleceram a produção de uma poesia híbrida através das plataformas virtuais.

PALAVRAS-CHAVE: Arnaldo Antunes; Poesia; Convergência; Tecnologias; Linguagem.

\author{
* poetaisa@yahoo.com.br \\ Centro Federal de Educação Tecnológica de Minas \\ Gerais - CEFET/MG - Departamento de Estudos de \\ Linguagem e Tecnologia - Letras/Mestrado.
}

ABSTRACT: The article proposes an analysis of Arnaldo Antunes' poetic in the context of the Culture of Convergence. The goal is to comprehend the signifying and iconic dimensions of Antunes' poems, perceiving that the Medias, in the process of convergence, strengthen the production of hybrid poetry through the virtual platforms.

KEYWORDS: Arnaldo Antunes; Poetry; Convergence; Technology; Language. 


\section{INTRODUÇÃO}

A poesia, nos primórdios de sua manifestação pela oralidade - e depois com a imprensa de Gutemberg -, mostrou que a mudança da expressão oral para o registro da escrita se traduz em distintas formas e sentidos. Tal transformação deixa entrever que a força da enunciação poética não está na voz e no livro, isolados como únicos meios de transmissão, ela está presente em ambos ou até conjugada, proporcionando diferentes formas de expressão. Os meios como suportes, segundo Müller (2012), se tornaram um dos fatores preponderantes para as transformações que a poesia vem sofrendo com as tecnologias. Os processos de incorporação da linguagem em diferentes suportes e mídias, nas dimensões concretas da materialidade dos suportes, foram e continuam a ser responsáveis por transportar esses sentidos até o receptor. Talvez um sentido novo, uma releitura ou um modo diferente de ver e de enunciar diante das transformações técnicas.

A poesia passou por essas transformações advindas das interfaces criadas com as novas tecnologias, rompendo o paradigma que definia sua apresentação por meio da rigidez da linearidade e da bidimensionalidade. Com o avanço da técnica e da produção poética, a poesia adquiriu versatilidade e flexibilidade verbal, pois mostrava facilidade em ser adaptada e produzida em novos suportes e maleável ao ser não só incorporada, mas também criada em novos espaços digitais. Os meios mudaram seus suportes conforme as tecnologias avançavam e criaram novas possibilidades performáticas para a linguagem poética.

As novas tecnologias em constante avanço têm conseguido converter diversas linguagens em dados digitais, mas também têm proporcionado novas ferramentas de criação para artistas e poetas, que se utilizam das máquinas tecnológicas para inventarem formas inovadoras de enunciação e apresentação plástica de suas obras. Como afirma Santaella (2005): "Tendo sua base na digitalização, os fatores de aceleração da co-evolução entre o homem e as máquinas destinadas ao tratamento da informação têm sido a hibridização das tecnologias e a convergência das mídias." 1

A poesia hoje circula num trânsito entre os meios, uma vez que essa relação híbrida e convergente entre o homem e a máquina refletiu no fazer poético. A poesia deu conta dessa convergência com os novos meios, apresentando-se atualmente em grande parte sob a forma digital. Pode-se encontrar a poesia em uma variabilidade de formas e formatos, que vão desde um poema disperso num espaço em branco de uma página a um videopoema.

No Brasil, a experiência de mudança radical nos paradigmas da expressão poética, em especial, no tocante à sua
1. SANTAELLA, Matrizes da Linguagem e Pensamento - sonora, visual e verbal: aplicações na hipermídia, p. 389. 
2. LOPES, Palavra, voz e imagem: a poética de Arnaldo Antunes, p. 9 produção, foi efetivamente com o poema concreto. Os poetas concretistas ao pensarem as questões icônicas-sígnicas das poesias (isto é, a verbi-voco-visualidade), constituíram um movimento que buscou dar maior visibilidade ao plano inicial, de rompimento com o pensamento clássico de leitura linear da poesia, que foi iniciado por Mallarmé, no século XIX. Um dos eixos do movimento concreto foi pensar nas aproximações do fazer poético com as novas tecnologias.

No decorrer dos anos 1980 e 1990 surgiram novas expressões que rapidamente se destacaram na mídia digital. Dentre elas, uma das significativas expressões poéticas é o multimidiático Arnaldo Antunes, com sua poética como arte e design, a palavra que se torna imagem e incorpora diferentes elementos de arte digital, tudo isso propiciado pelos meios.

$\mathrm{O}$ artista Arnaldo Antunes opera sua poiesis numa interação de múltiplas dimensões e possibilidades numa "fronteir de códigos e linguagens [...] reinventando a maneira de fazer poesia, por meio de uma linguagem híbrida e multimidiática" $^{\prime 2}$. A poesia arnaldiana deu conta dessa convergência com os novos meios, apresentando-se em grande parte na forma digital.

A poética de Arnaldo Antunes se insere dentro da cultura da convergência, pois seu processo de criação e produção demonstra a mudança de percurso da poesia concebida na folha em branco em direção à digitalização. Sua poesia é versátil e flexível, adaptando-se a diferentes suportes e entrelaçando de maneira inusitada a imagem, o som, o movimento e a escrita, configurando assim uma poesia híbrida.

A denominação dada a Arnaldo Antunes, concebido como artista-poeta multimidiático, leva a pensar essa relação do poeta com a mídia. Nesse sentido, o artigo se propõe a analisar produção poética de Arnaldo Antunes, em meio digital. Em seu DVD “NOME” e no site www.arnaldoantunes.com.br podem-se ver diversos de seus trabalhos, sendo a maioria apresentada digitalmente. Nele, o autor apresenta duas classificações, notadamente curiosas, para as suas poesias: "digitais" e "poesias visuais". Partindo dessa percepção, o que se observa é a distinção de Antunes no trato da imagem e da palavra como formas diferentes de expressão de sua poiesis. A questão que guia a análise é como a poesia de Arnaldo Antunes se configura num trânsito constante da cultura da convergência?

A partir de leituras bibliográficas e pesquisa exploratória do site e do DVD "NOME" de Arnaldo Antunes, o corpus de análise será constituído pelos videopoemas "Fênis" e "Dentro", pois ambos passaram por um processo de experimentação em diferentes mídias. Para esta pesquisa utilizou-se a análise de imagens estáticas e em movimento com abordagem descritiva pelo método qualitativo de PENN 
3. MARTINS, Poesia e tecnologia, p. 2.

4. MÜLLER, Linhas imaginárias: poesia, mídia, cinema , p. 8.
ROSE (2012). Pretende-se analisar as apropriações dessa cultura da convergência feitas por Arnaldo Antunes em sua produção poética.

Partindo dessa percepção, o que se observa é a distinção de Antunes no trato da imagem e da palavra como formas diferentes de expressão de sua poiesis. A proposta busca situar a poesia no contexto da convergência na contemporaneidade, por conta dos avanços tecnológicos advindos desde o surgimento da imprensa de Gutemberg. Diante desse processo, propõe-se expor os desdobramentos mais específicos da poesia nesse contexto (da poesia com a tecnologia e a mídia) e que foram precedidos pelo movimento concretista, no caso brasileiro, especificamente a poética de Arnaldo Antunes.

\section{POESIA E MÍDIA: A CULTURA DA CONVERGÊNCIA}

A materialidade da arte é determinada pelos meios técnicos e, sobretudo, no mundo contemporâneo, pelos meios tecnológicos utilizados na sua produção.

A relação homem-máquina vem paulatinamente modificando os modos de produção e consequentemente os meios inseridos nesse processo. Segundo Müller (2012), "diferentes mídias criam diferentes poesias" ${ }^{4}$, para se pensar em mídia, deve-se compreendê-la numa dimensão além do suporte propriamente dito (os meios). Müller (2012) não considera que todo meio seja necessariamente uma mídia para ele mídia envolve processos de trocas, uma sincronia de informação, produção e comunicação. A mídia é um 'elemento' de relação com outros campos e outros sistemas sígnicos, resultando na sua convergência.

A convergência das mídias se realiza pela constituição de fluxos de informações que se entrelaçam e não o processo tecnológico que une múltiplas funções num único suporte. Percebe-se, então, a convergência como uma interação e não como a sobreposição de tecnologias. Jenkins (2009), em seu livro "A cultura da convergência" mostra que a convergência é um conceito antigo que assume novos significados, o autor compreende as mídias como "um fluxo de conteúdos através de múltiplos suportes midiáticos"s. A interação entre antigas e novas mídias vão caracterizar um processo de hibridização que converge para uma nova poética que torna a poesia digital difícil de ser classificada e caracterizada como um segmento literário.

Antunes mostra essas transformações constantes nos poemas, que primeiro produziu graficamente, depois trabalhou com recursos analógicos e finalmente com a poesia digital Nos seus trabalhos percebe-se a presença de diferentes linguagens como a incorporação do cinema, do som com mixagem da voz e trilhas sonoras musicais, palavras em movimento se dispersando no espaço, fragmentos de letras etc. Nisso, a presença das mídias em sua produção se tornou um
5. JENKINS, Cultura da Convergência: a colisão entre os velhos e novos meios de comunicação, p. 29. 
6. SANTAELLA, Matrizes da Linguagem e Pensamento aplicações na hipermídia, p. 380 fator preponderante pelas apropriações que ele faz do uso da fotografia, do filme, do computador etc.

Diante do fenômeno da cultura da convergência, a cibercultura adensa essa relação do homem com as novas tecnologias, uma vez que ela configura um espaço onde as produções são possíveis de serem difundidas pelos meios, através da plataforma virtual. A poesia inserida e criada nessa plataforma cyber, apresenta diversas configurações que se iniciaram com a transição da poesia escrita para a poesia sonora (gravação de áudio em Cd-rom), em seguida a poesia escrita digitalmente, a poesia em movimento através de vídeos (suporte betacam, antigo VHS ou adobe flash), dentre outras.

Antunes é parte desse cenário quando se vê em suas produções a incorporação de diferentes experiências com os meios e mídias, como é o exemplo dos poemas "Fênis" e "Dentro". Diante desse avanço técnico nas incorporações midiáticas e o seu uso na contemporaneidade, Santaella (2005) mostra uma preocupação quanto à abordagem das linguagens nesse processo de convergência:

Dentro dessa lógica, como ficam as linguagens em relação aos meios ou mídias? Meios, como o próprio nome diz, são meios, isto é, suportes materiais, canais físicos nos quais as linguagens se corporificam e através dos quais transitam. ${ }^{6}$
Santaella (2005), no estudo das matrizes da linguagem, mostra que as linguagens se articulam de acordo com cada mídia, uma vez que "[...] são as linguagens, os processos sígnicos que muito justamente são transportados e transitam pelas mídias." As mídias possibilitam a circularidade e diálogo entre as diferentes matrizes ainda que os meios podem não definir o conteúdo, mas têm forte influência sobre ele.

Embora sejam responsáveis pelo crescimento e multiplicação dos códigos e linguagens, meios continuam sendo meios. É certo que cada mídia particular produz modificações específicas em cada matriz de linguagem. Por exemplo, o visual da fotografia não é o mesmo que o visual do cinema, assim como este não é o mesmo que o da televisão, nem este igual ao do vídeo.

O computador tornou-se uma ferramenta que possibilitou ampliar as perspectivas de criação poética com um diálogo mais intenso com a arte, tornando a poesia uma obra de arte. Relembrando que a poesia concreta teve uma íntima relação com a arte - o concretismo criou objetos artísticos com as palavras. O texto adquiriu elementos da verbo-voco-visualidade, sendo a palavra articulada como imagem, som e verbo simultaneamente, com movimentos e sons que no plano impresso não eram possíveis de serem produzidos.

Os meios acentuaram as possibilidades criativas e forneceram novos dispositivos e espaços de criação. A palavra-imagem
7. SANTAELLA, Matrizes da Linguagem e Pensamento aplicaçốes na hipermídia, p. 380.
8. SANTAELLA, Matrizes da Linguagem e Pensamento 
9. LOPES, Palavra, voz e imagem: a poética de Arnaldo Antunes, p. 46

10. SANTAELLA, Matrizes da Linguagem e Pensamento aplicaçốes na hipermídia, p. 381 e a imagem da palavra predominam nesse processo, alterando a característica textual e tradicional da linearidade. Lopes (2007) ressalta que o poeta dispõe-se da linguagem como forma de buscar novas expressões, utilizando recursos que possibilitam ir além da tradicional palavra escrita:

O poeta não utiliza a linguagem comum, mas a desvia do uso convencional, transformando-a numa outra linguagem, a da poesia. O desvio e a transgressão da linguagem, são, portanto, a desverbalização da palavra, um modo de transformá-la em palavra imagética. ${ }^{9}$

Essa relação da palavra com a imagem é o que define a escolha pela hipermídia como plataforma de criação e produção poética, pois ela permite que um conjunto de textos, sons, imagens, vídeos e outros se articulem. O hibridismo presente nos signos e linguagens é visto como elemento basilar na cibercultura, como afirmou Santaella (2005): "A escolha da hipermídia não é causal, visto que o hibridismo de signos e linguagens é nela levado ao paroxismo." 10

Diante desse paroxismo apontado por Santaella (2005) Lev Manovich (2005) faz apontamentos sobre a relação da arte com as novas mídias, essa produção incessante do século XXI pelo computador. Segundo ele, há uma indefinição da arte das novas mídias, uma difícil caracterização de um segmento cada vez mais presente nos dias de hoje.
Se todos os artistas agora, independentemente de suas mídias preferidas, também usam rotineiramente os computadores digitais para criar, modificar e produzir obras, precisamos de um campo especial de arte em novas mídias? Como as mídias digitais e da rede estão rapidamente se tornando onipresentes em nossa sociedade e como a maioria dos artistas passou a usá-las rotineiramente, o campo das novas mídias está enfrentando o risco de tornar-se um gueto [...] Então, o que são exatamente as novas mídias? E o que são as artes das novas mídias? [...] cibercultura concentra-se no social e na rede; as novas mídias concentram-se no cultural e na computação. [...] as novas mídias são objetos culturais que usam a tecnologia computacional digital para distribuição e exposição. ${ }^{11}$

Com isso, percebe-se a intensidade que essa hipermídia encontra-se presente e tão marcadamente sinalizada nas obras poéticas do multimidiático Arnaldo Antunes. A denominação de multimidiático ao poeta-artista Antunes, não foi proposital. Por que não defini-lo como ciberpoeta uma vez que suas produções se inserem nesse quadro da cibercultura?

\section{CIBERPOESIA OU POESIA MULTIMIDIÁTICA? COMO}

\section{DEFINIR A POETICA DE ARNALDO ANTUNES?}

$\mathrm{Na}$ contemporaneidade, uma questão filosófica é colocada em pauta por diversos pensadores e teóricos, a respeito do lugar ocupado pela poesia hoje diante das transformações
11. MANOVICH, Novas mídias como tecnologia e ideia: dez definições, p. 26-27.
EM TESE

BELO HORIZONTE

v. 19

N. 2

AG0.-OUT. 2013

OLIVEIRA. A poética de Arnaldo Antunes na cultura da convergência

P. $40-55$ 
tecnológicas que a perpassaram. Esta colocação foi amplamente explorada por Adalberto Müller (2012) e, com relação às incertezas do futuro da poesia, encontramos as abordagens de Ernesto Manuel de Melo e Castro (2008) através da releitura da poiética na contemporaneidade. Porventura essas questões surgiram e se intensificaram com os avanços trazidos pelas novas tecnologias.

A poesia experimental na contemporaneidade persiste como forma de descobrir suas infinitas possibilidades. Contudo, torna-se difícil caracterizar uma poesia produzida no computador: ela deixa de ser palavra e passa a se tornar imagem? Ou é uma palavra-imagem cuja performance não linear evidencia um texto capaz de configurar uma outra dimensão prática e criativa?

Arnaldo Antunes é de uma geração posterior aos concretistas, sua carreira teve início nos anos 1970, quando havia apenas computadores em grandes laboratórios no Brasil, e só começou a despontar duas décadas depois, em 1990 com os computadores pessoais. É natural que sua produção musical, poética e artística tivesse uma forte ligação com as referências da época, como mostra Lopes (2007):

Focalizar a maneira como o poeta produz sua poética é importante, pois essa é resultado do cruzamento tanto das culturas como das multimídias. Seu processo poético mostra uma asso- ciação de sua poesia com o experimentalismo e com a cultura Pop. ${ }^{12}$

Arnaldo Antunes, numa entrevista à revista Cult, transcrita por Lopes (2007), relata sobre a influência na sua produção e como ela transita por diferentes linguagens:

No meu caso, [a poesia] tem uma influência que veio da poesia concreta, mas não só. A própria tradição da música popular brasileira, além da cultura pop e da tradição do rock'n'roll, acabam influenciando não só minha produção musical, mas também a produção poética. ${ }^{13}$

Analisar a produção poética contemporânea requer um olhar atento ao que cerca o poeta-artista, estudar não só o seu modo de fazer poesia, e os recursos para tal, mas o uso que ele faz da poesia como uma linguagem em trânsito. Seria suficiente a partir da definição de sua poética definir o poeta? E na atual cultura de massa, cada vez mais os autores se individualizam porque suas obras se tornaram singulares e irreprodutíveis, incapazes de serem copiadas em grande escala como um produto ou bem a ser consumido adquirindo características típicas e distinguíveis.

Foucault (2005), no estudo “O que é um autor?”, aponta para esse direcionamento que a produção leva a definir o escritor: "a marca do escritor não é mais do que a singularidade
12. LOPES, Palavra, voz e imagem: a poética de Arnaldo Antunes, p. 91.

13. LOPES, Palavra, voz e imagem: a poética de Arnaldo Antunes, p. 91. 
14. FOUCAULT, O que é um autor?, p. 268.

15. FOUCAULT, O que é um autor?, p. 268.

16. FOUCAULT, O que é um autor?, p. 270. de sua ausência; é preciso que ele faça o papel do morto no jogo da escrita." ${ }^{14}$. Para Foucault, a poiesis ou a escrita está livre de se atrelar a alguma linha de expressão ou segmento artístico/literário,

[...] ela basta a si mesma, e por consequência, não está obrigada à forma da interioridade; ela se identifica com a própria exterioridade desdobrada. O que quer dizer que ela é um jogo de signos comandado menos por seu conteúdo significado do que pela própria natureza do significante. ${ }^{15}$

A escrita no âmbito das redes digitais rompe a regularidade e busca o seu caminho próprio através das experimentações, o que torna difícil definir e analisar a obra para definir o autor ou vice e versa: "é insuficiente afirmar: deixemos o escritor, deixemos o autor e vamos estudar, em si mesma, a obra. A palavra 'obra' e a unidade que ela designa são provavelmente tão problemáticas quanto a individualidade do autor." 16

Antunes é músico, performer, poeta, artista plástico e artista digital, todos os seus trabalhos incorporam um pouco de si, um pouco de tudo que é e faz. Suas obras incorporam suas experiências em cada área que atua, os elementos externos como a música, a poesia, a família, a arte estão inseridos em suas expressões de forma que se não consegue desarticular sua persona-artística, o eu e o artista.
Assim Barthes (2004), em "A morte do Autor”, considera que a obra é aberta e dotá-la de autoria é basicamente arriscar ignorar os elementos externos que a compõem:

Uma vez o autor afastado, a pretensão de 'decifrar' um texto torna-se totalmente inútil. Dar um autor a um texto é impor a esse texto um mecanismo de segurança, é dotá-lo de um significado último, é fechar a escrita. Esta concepção convém perfeitamente à crítica, que pretende então atribuir-se a tarefa importante de descobrir o autor (ou as suas hipóstases: a sociedade, a história, a psique, a liberdade) sob a obra: encontrado o autor, o texto é explicado. ${ }^{17}$

A partir dessa discussão, como definir a poética de Arnaldo Antunes num contexto de constante transformação? A convergência é a evidência de que a obra não se fecha em si mesma, não se esgota na sua forma e leitura, é um conjunto de linguagens que dialogam entre si e circulam por diferentes mídias.

A poesia de Antunes se encontra num espaço globalmente conhecido como cyber, numa rede de circulação que poderia muito bem defini-la como ciberpoesia, pois parte de sua produção inicia-se no computador e para melhor compreendê-la requer essa plataforma virtual para que ela aconteça.
17. BARTHES, $A$ morte do autor, p. 4-5.
EM TESE

BELO HORIZONTE

v. 19

N. 2

AG0.-OUT. 2013

OLIVEIRA. A poética de Arnaldo Antunes na cultura da convergência

P. $40-55$ 
18. A poética analisada é o conjunto da obra do autor, o que é diferente da poiésis quando se trata do ato de criação fabulação.
A definição multimidiática conferida ao poeta justifica-se pelo fato de o poeta se apropriar de vários meios como forma de difundir a sua poética ${ }^{18}$. Há uma confusão conceitual que foi esclarecida anteriormente por Santaella (2005) entre mídia e meios (suportes). Confundem-se as mídias com os suportes. Arnaldo Antunes é um autêntico explorador de alternativas de disseminação de seus trabalhos utilizando-se de diversas maneiras de veicular sua obra através dos meios, mas é pela mídia que melhor se configura a sua produção. Embora ela aconteça através das mídias, seria então esta definição suficiente para alcançar a sua linguagem de expressão? O uso reiterado de mídias em seus trabalhos explica a sua definição poética como multimidiático?

Em seu site ele apresenta as poesias visuais distintas das obras digitais. $\mathrm{O}$ critério apontado por ele nessas intitulações não é suficiente para enquadrá-lo na ciberpoesia e por quê? A ciberpoesia parte do princípio de que a poesia deve ser produzida no computador e ser este o meio o qual ela se configura. Não seriam então as obras intituladas "digitais" uma ciberpoesia? As obras "digitais" transitam pelo virtual, mas são constitutivas por elementos imagéticos feitos no computador. Há uma mistura de arte com uma linguagem poética.

Os videopoemas "Fênis" e "Dentro" estão na categoria dada pelo poeta de poesia visual. Ambos os poemas transitaram por diferentes mídias até chegar ao seu formato final, cuja versão final é um misto de linguagens tais quais: som, cine (movimento), verbo (a escrita), corpo, multimídia, digital, imagem etc. Serão analisadas as apropriações feitas por Antunes da produção dessas poesias a qual ele classifica de "visuais".

Todas as suas produções incorporam o uso do recurso do computador, o que não descarta a possibilidade de serem consideradas como ciberpoemas. O fato de convergir diferentes mídias possibilita uma produção diferente das produzidas unicamente pelo computador

\section{A POÉTICA ARNALDIANA: POESIA VISUAL X POESIA DIGITAL OU POESIA MIDIÁTICA? A PALAVRA-IMAGEM/ \\ IMAGEM DA PALAVRA}

As poesias arnaldianas são bastante experienciais pelo fato de Antunes, em seus relatos em "Poesia Visual Vídeo Poesia" de Ricardo Araújo (1999), apresentar as dificuldades de encontrar a melhor forma de representar o poema como ele o concebia originalmente. As primeiras tentativas foram limitadas devido aos recursos técnicos da época, então se vê uma trajetória de produções diferentes do mesmo poema.

Com o avanço das tecnologias, Arnaldo Antunes foi motivado pela possibilidade de poder realizar a arte-movimento no seu poema conforme ele imaginou/projetou a partir das potencialidades da rede virtual. A proposta para o poema 
intitulado "Dentro", foi linearmente concebida como: "De Dentro, Entro, Centro sem Centro..." teve uma versão original publicada no livro "Tudos". O poeta buscou romper a linearidade do poema, ele procurou eliminar os espaços entre as linhas existentes, dotando o poema com um aspecto visual de um formato de curva com distorções do texto.

Antunes fez três versões desse poema cada qual em formas diferentes de apresentação até alcançar a forma de videopoema. A primeira versão foi um trabalho gráfico com fundo branco na mesma forma que foi concebida e publicada no livro "Tudos". A variação da primeira versão para a segunda foi o fundo que mudou de branco para preto com letras brancas quando editou para o livro "Nome". Ainda na segunda versão publicada no "Nome", o poema apresenta variações apenas no termo Dentro que vai ganhando formas distintas e aumentando a sua concavidade e tamanho. Na terceira versão o poema ganha uma versão mais elaborada através de uma interação de vários trabalhos técnicos utilizando a endoscopia para gravar o som e a imagem do poema dentro da sua garganta. A representação da poesia sendo exteriorizada, a poesia que sai de dentro do poeta (Fig. 1).
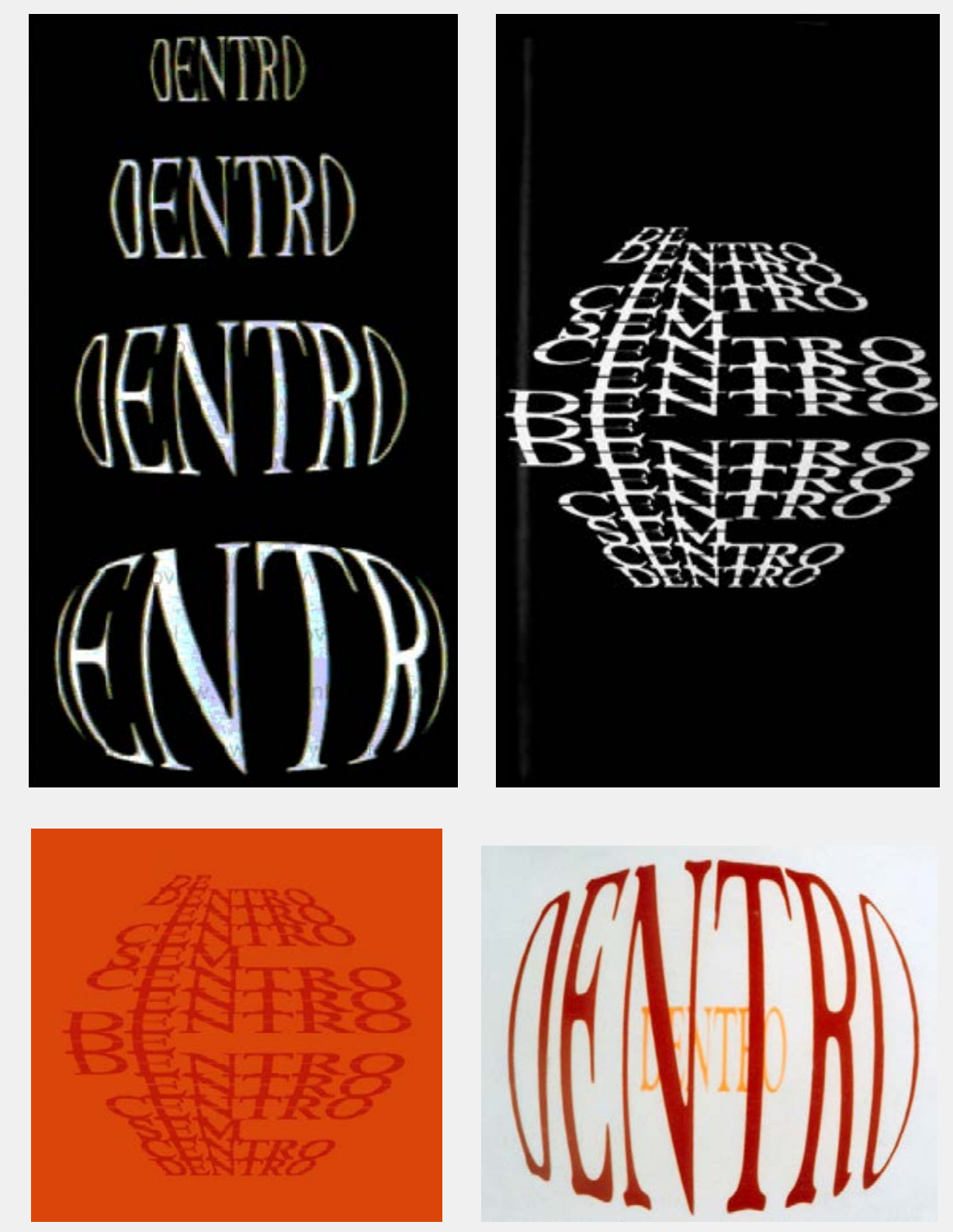

FIGURA 1
FIGURA

al "Dentro", diferentes versões de 1990, 1991, 1992 e 1993, respectivamente

Fonte: Disponive/ em: <http://www arnaldoantunes.com.br/sec_livros imagens.php? id $=140>$. Acesso em $28 / 04 / 2013$ 
19. ARAÚJO, POESIA VISUAL VÍDEO POESIA, p. 107.
Esse poema, "De Dentro, Entro, Centro sem Centro...”, tinha uma versão original feita no livro 'Tudos', que já era uma versão circular onde os espaços entre as linhas eram eliminados. Então, já tinha um pouco da sugestão de distorção de tipologia, sem ter, ainda, a coisa da tridimensionalidade, que foi o que eu quis incluir ao fazer a animação. [...] Eu queria que a palavra "dentro" pudesse ficar côncava e convexa [...] aparecesse escrita dentro de uma superfície que viesse para fora e para dentro, literalmente [...] que foi uma ilusão de ótica que pareceu ser impossível de ser realizada. E, então, ficou apenas convexo. Daí tive a ideia dela ir saindo para fora da tela e de "de dentro" da palavra "dentro" surgindo outra palavra; e aí o poema foi se fazendo nessa coisa de explodir um pouco para fora da tela. [...] acabei adaptando um pouco a idéia do poema, porque, a partir das limitações e dos recursos que eram disponíveis eu fui adaptando o roteiro. ${ }^{19}$

Após muitas tentativas e experiências seguidas com as versões anteriores, que foram feitas em plataformas gráficas, finalmente o poeta converge diferentes mídias numa produção cine. Uma aproximação da oralidade com a imagem e a escrita, onde mesclou imagem, vídeo, movimento e áudio, conforme descreve o autor:

A primeira coisa que me seduziu nessa ideia de 'Video Poesia' foi a questão da inserção de movimento palavra escrita, inserir movimentos na escrita, que é uma coisa que se consegue com recursos da animação. Para mim, foi essa dimensão o que me seduziu em primeiro lugar. [...] Além disso, há a ocorrência simultânea do som. Você tem várias possibilidades de explorar essa relação da palavra falada ou cantada simultaneamente. [...] a questão da simultaneidade de duas ocorrências do verbal: a palavra ouvida ou cantada recebida pelo som, e a palavra escrita percebida pelo olhar. ${ }^{20}$

Arnaldo Antunes mostra que em seu processo de construção poética, o poema na forma que ele concebia só se tornou possível após a convergência das mídias. Na versão final, publicada no DVD "NOME" (Fig. 2) o poema "Dentro" sai da esfera gráfica e entra para uma esfera tridimensional e performática, em que o videopoema leva o poema para dentro da oralidade. Ou seja, o poema ecoa da sua voz através da sonda endoscópica e vai para o vídeo com imagem e letras. Esse videopoema é uma tradução icônica do processo de oralidade para a escrita e a imagem, onde a palavra ecoada se transforma em imagem e a imagem da palavra movimenta-se no espaço do papel e da tela. Kobs (2011) mostrou como as artes gráficas são elementos predominantes na produção de Antunes, o quanto a visualidade impera em suas obras, sua poesia é proeminentemente visual.
20. ARAÚJO, POESIA VISUAL VÍDEO POESIA, p. 105-106. 
FIGURA 2

Videopoema "Dentro": a palavraimagem, 2005

Fonte: NOME, 2005 - DVD

21. KOBS, As relações entre imagem e palavra na produção contemporânea de Arnaldo Antunes, p. 276.

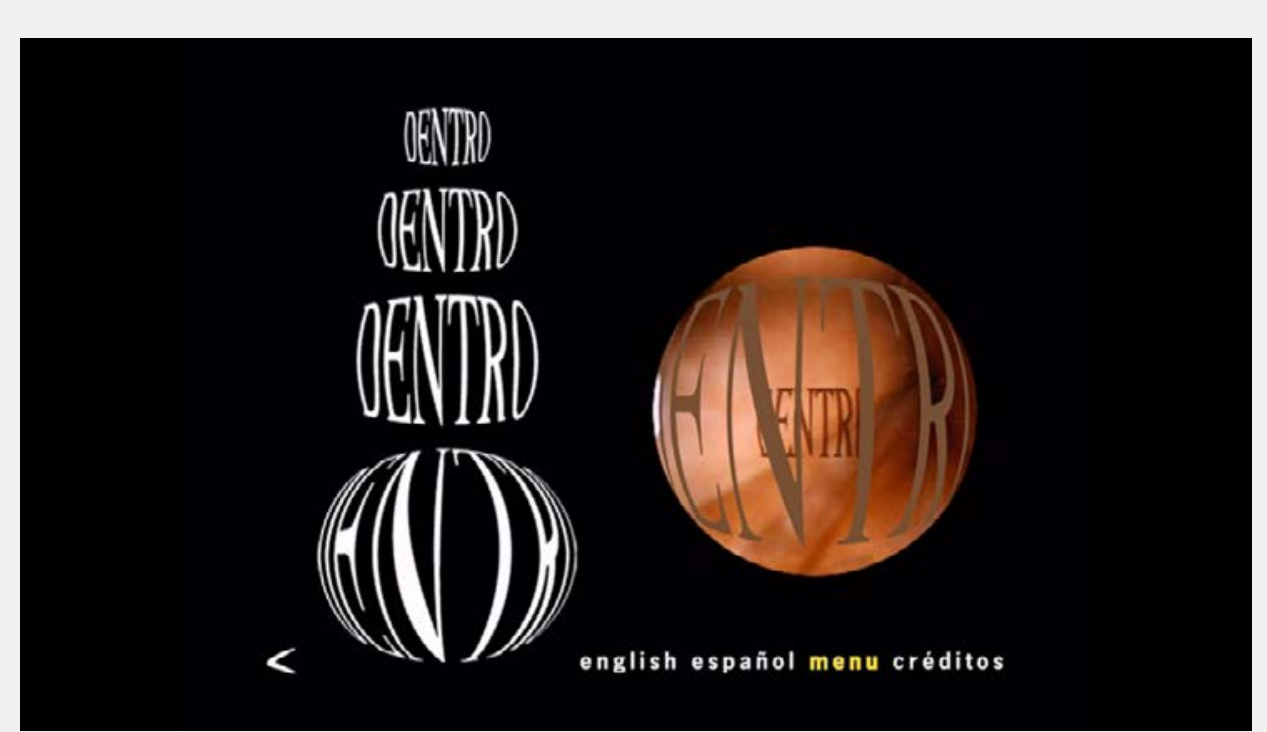

Kobs (2011) mostra como "a imagem aparece inscrita no texto"22, com isso diferentes signos surgem interligados numa relação entre imagem e palavra, construindo o sentido poético que Antunes busca e a palavra por si só não alcança.

O poema "Fênis" tem a mesma proposta, porém passou por um processo mais direto da palavra para a imagem e para o movimento. $\mathrm{O}$ processo inicial foi gráfico até se converter num poema audiovisual em DVD no ano de 2005, uma vez que a versão original deu-se em 1993 através de animações gráficas (Fig.3).

FIGURA 2

Partindo da ideia de transformar a palavra num ícone, uma imagem icônica, salientamos que ela não perde o seu papel, apenas assume um sentido novo, e esse sentido tradutório pode ser mais significativo ou não que a própria escrita. Mas a relação imagem e texto é interdependente nas obras de Antunes, a todo o momento elas se correlacionam, segundo afirma Kobs (2011).

Tomando a imagem como referência, ela pode ser superior, inferior ou equivalente à palavra. Na produção literária de Arnaldo Antunes, a imagem é elemento absolutamente necessário e, em razão disso, são privilegiadas, em seus textos, as relações de predominância ou de igualdade da imagem diante da escrita. ${ }^{21}$
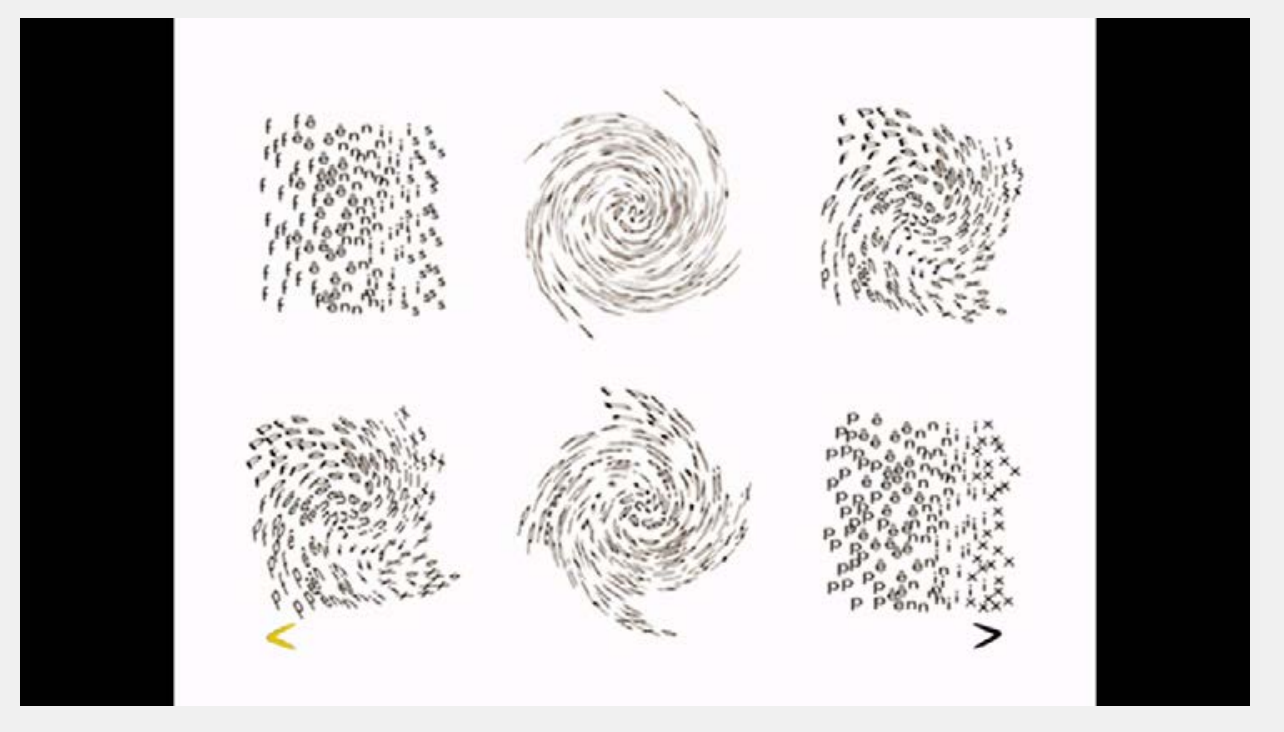

FIGURA 3
22. KOBS, As relaçóes entre imagem e palavra na produção contemporânea de Arnaldo Antunes, p. 280.

FIGURA 3

Poema "Fênis", 1993, Arnaldo Antunes

Fonte: NOME, 2005 - DVD 
O poema "Fênis" elaborado através de gráficos animados, na primeira versão, mostra uma transformação da palavra "fênis" em "pênis", a palavra renasce de uma mistura cuja imagem lembra um redemoinho, onde a rotação em espiral leva as palavras a transmutarem em uma nova palavra, "pênis".

O fênis (A fênix, uma ave que renasce das cinzas) é conhecido mitologicamente por sua transformação e renascimento das cinzas. No vídeo, da segunda versão (Fig.4), as palavras se desfazem em letras soltas como o pó em movimento de circulação e redemoinho, acompanhado de um som de uma respiração ofegante como se nos remetesse ao ato sexual. A palavra "fênis", no vídeo, desaparece e surge o termo "pênis". $\mathrm{O}$ videopoema mostra um redemoinho num líquido lactoso em que a palavra se liquefaz como se escoasse pelo ralo para dar lugar a uma nova.

Esse poema mostra o processo gráfico de animação inicial e o atual no qual ao ser produzido no vídeo com imagem, som e palavras em que se evidenciam a presença do uso de diferentes mídias. Elas possibilitaram uma produção próxima à ideia da imagem da palavra se modificando através do movimento. A imagem conectada ao áudio no poema simula duas coisas: o som do movimento do redemoinho e o som do ato sexual que alude ao termo pênis.

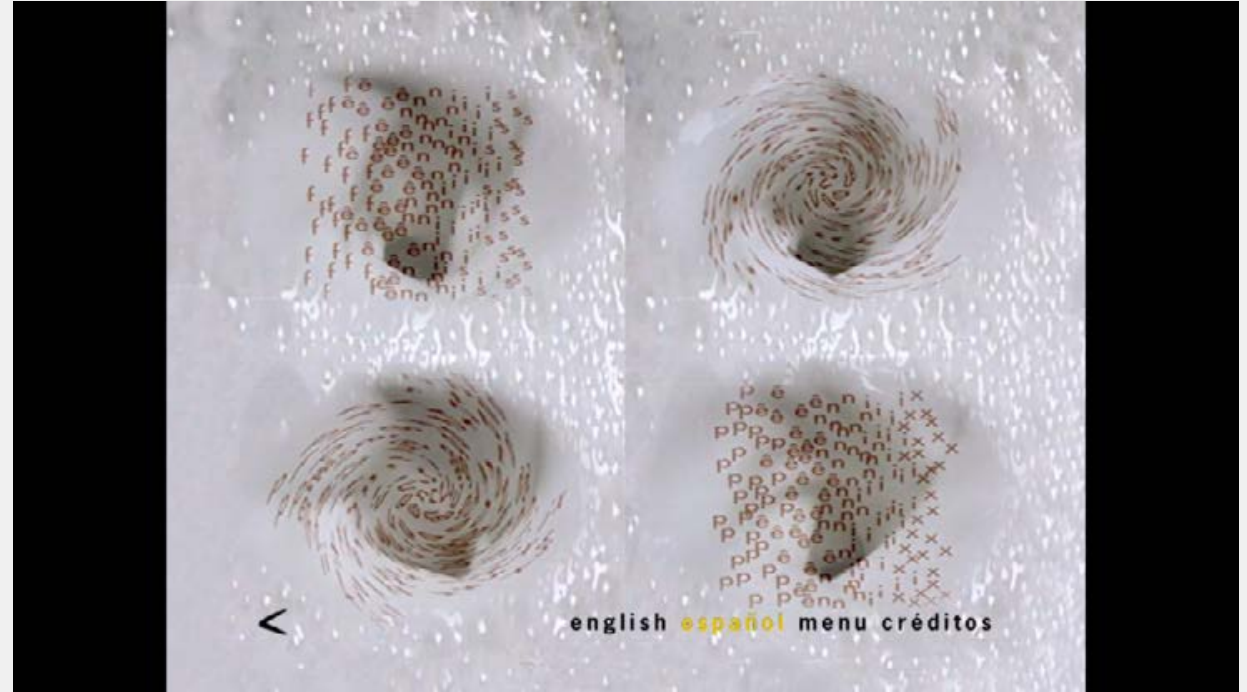

FIGURA 4

Segundo Deleuze (2005), o uso da imagem se tornou um clichê e caracteriza uma civilização que se traduz em imagens, as palavras se perdem: "Civilização da imagem? Na verdade uma civilização do clichê, na qual todos os poderes têm interesse em nos encobrir as imagens, não forçosamente em nos encobrir a mesma coisa, mas em encobrir alguma coisa na imagem." 23

Arnaldo Antunes apresenta uma poética em que predomina a imagem, por ser tão marcada em suas produções e muito difundida através dos meios visuais. Antunes é a referência da poética contemporânea que se faz valer pelo uso da imagem nas exposições de obras visuais, espetáculos performativos dentre outros. Sua expressão permeia uma
FIGURA 4

Videopoema "Fênis", Arnaldo Antunes

Fonte: NOME, 2005 - DVD

23. DELEUZE, A Imagem-tempo, p. 32. 
24. LOPES, Palavra, voz e imagem: a poética de Arnaldo Antunes, p. 35. linguagem visual da palavra, que transita por diferentes códigos, convergindo mídias, tornando a poesia de Antunes como multimidiática.

E quando a ciberpoesia está em pauta com suas indefinições conceituais, ela incorpora a produção multimidiática Quando Antunes utiliza diferentes mídias na sua produção ainda assim ele trabalha sua poética no computador. E através da convergência das mídias como vídeo, áudio, outros hardwares e softwares digitais, o uso do computador é a plataforma efetiva para que o seu trabalho se torne também digital e se insira na rede.

A denominação cyber é global a toda e qualquer produção poética por computador. Considerando esse ponto de vista, a produção arnaldiana agrega diferentes tecnologias e perpassa pela rede seja como produtora ou difusora da sua poética. Augusto de Campos já considerava Antunes poeta dessa seara, segundo Lopes (2007)

Augusto de Campos considera Arnaldo Antunes ciberpoeta, por subverter os conceitos tradicionais da estética ao desenvolver o trânsito poético nos códigos multimidiáticos. A cibercultura também prescinde da interação com a internet. Como afirma Lev Manovich (2005, p. 26): 'Eu definiria a cibercultura como o estudo dos vários fenômenos sociais associados à internet e outras formas de comunicação em rede. ${ }^{24}$
A obra de Antunes transita entre o gráfico e o virtual, ele parte da palavra para conceber o poema e a partir da poesia escrita ele experiencia em diferentes formas de traduzi-la em movimento, daí ele incorpora outras mídias que agregam sentido ao poema. E todo esse processo pensado via computador, utiliza a tecnologia virtual como a plataforma base para que seus poemas se concretizem. Lopes (2007) mostra esse processo percorrido por Antunes e demonstra que sua poesia está em constante trânsito com a palavra pela arte apropriando-se ao máximo das tecnologias disponíveis.

Antunes dedica-se ao trabalho gráfico e diagramático na cibercultura. A palavra é o seu material artístico, que frequenta uma metodologia marcada pela música, poesia, vídeo, clipe e outras linguagens inseridas na tecnologia deste século. O trânsito poético articula os códigos em territórios híbridos, sem perder sua poeticidade. Os inúmeros poemas arnaldianos, que se tornaram canções, têm um caráter plástico, visual e móvel. Esse mesmo caráter se apreende no projeto cinematográfico, que inclui a filmagem do corpo da palavra e do corpo humano, no projeto Nome (1993), trabalho tecnológico realizado com a ajuda do computador. ${ }^{25}$

As palavras se tornam imagens e a imagem das palavras se destaca dando sentido aos videopoemas. Nas obras analisadas prevalecem a visualidade enquanto, que a arte digital se configura apenas quando a produção é exclusivamente
25. LOPES, Palavra, voz e imagem: a poética de Arnaldo Antunes, p. 36. 
na rede, no ciberespaço; Sob esse aspecto é possível afirmar que, a poesia é construída pela interação entre redes. Na poiesis de Antunes vê-se uma convergência para que a produção aconteça, mas não está completamente fora da ciberpoesia pelo fato de suas produções partirem do uso tecnológico do computador.

\section{CONSIDERAÇÕES FINAIS}

A relação da poesia, sua linguagem poética, com a mídia é anterior ao computador, embora o trato com a palavra como imagem ou arte era evidente nas produções dos poetas concretistas. A poesia ganhou força e adesão ao fortalecer essa relação da criação poética através da tecnologia, o computador.

A produção arnaldiana se configura pelo uso das tecnologias para representar os signos verbais e não-verbais que se traduzem numa interação entre diferentes códigos através da palavra e a arte. Ele mantém o uso constante da palavra em trânsito na rede, configurando-a em diferentes traduções poéticas pela convergência das mídias. O poeta faz jus à denominação de multimidiático quando ele se apropria dos recursos técnicos-midiáticos na sua produção, elevando-a a múltiplas dimensões.

Arnaldo Antunes soube se apropriar das mídias que deram um caráter mais significativo e icônico às poesias. Seus poemas demonstram uma evolução tal qual se vê nas matrizes originais, como se fossem poemas concretos, e seguiu o sonho dos concretistas de usufruir das tecnologias como plataforma de produção poética, Antunes alcançou essa perspectiva.

A título de consideração final, cabe ressaltar que Arnaldo Antunes é um poeta multimidiático é também um ciberpoeta. Mas vale lembrar que a ciberpoesia é uma caracterização muito ampla e difícil de ser definida ou classificada. As possibilidades de compreender a obra arnaldiana não se esgotam, vale a pena repensar as poesias intituladas por ele como "digitais” que não foi possível ser explorado. Mas essas poesias podem trazer novas elucidações no tocante à produção cyber de Antunes.

Outro aspecto interessante que foi abordado é reconhecer qual o lugar ou espaço da poesia contemporânea, como classificá-la na contemporaneidade uma vez que ela está em constante mutação com as novas tecnologias. As tecnologias e as mídias têm sofrido com a obsolescência que cria possibilidades cada vez mais inovadoras de produção e interferem no poder criativo.

Arnaldo Antunes é o poeta das múltiplas mídias, o poeta da imagem, da palavra-imagem (imagem da palavra). Ele consegue contemplar a palavra conferindo a ela um status 
imagético e performático proporcionado pela convergência midiática sem deixar que a palavra perca a sua função precípua na poiesis.

\section{REFERÊNCIAS}

ANTUNES, Arnaldo. Arnaldo Antunes. Disponível em: <http:// www.arnaldoantunes.com.br/new/>. Acesso em: 16 ago. 2013

ARAÚJO, Ricardo. POESIA VISUAL VÍDEO POESIA. São Paulo: Ed.Perspectiva, 1999. (Debates, 275).

BARTHES, Roland. A morte do autor. In: BARTHES, Roland. Rumor da Língua. São Paulo: Martins Fontes, 2004

DELEUZE, Gilles. A Imagem-tempo. São Paulo: Brasiliense, 2005

FOUCAULT, Michel. O que é um autor? In: FOUCAULT, Michel. Estética: Literatura e Pintura Música e Cinema. 2ed. Rio de Janeiro: Forense Universitária, 2006

JENKINS, Henry. Cultura da Convergência: a colisão entre os velhos e novos meios de comunicação. 2.ed., São Paulo: Aleph, 2009

KOBS, Verônica Daniel. As relações entre imagem e palavra na produção contemporânea de Arnaldo Antunes. MISCELÂNEA Revista de Pós-Graduação em Letras - UNESP: Assis. v.9, p. 274-289, jan./jun. 2011. Disponível em: <www.assis.unesp. br/ miscelanea>. Acesso em: mar. 2013
LOPES, Márcia Plana Souza. PALAVRA, VOZ E IMAGEM: A

POEETICA DE ARNALDO ANTUNES. Dissertação de Mestrado Letras, PUC-SP: São Paulo, 2007

MANOVICH, Lev. Novas mídias como tecnologia e ideia: dez definições. In: LEÃO, Lúcia (Org.). O Chip e o caleidoscópio: reflexões sobre as novas mídias. São Paulo: Editora Senac, 2005. p. 23-50.

MARTINS, P. F. da S. Poesia e tecnologia. Texto digital, Florianópolis, ano 3. n.1, julho 2007. Disponível em: <http:// www.textodigital.ufsc.br/num04/patricia.html >. Acesso em: 24 dez. 2011 e 26 mar. 2013.

MÜLLER, Adalberto. Linhas imaginárias: poesia, mídia, cinema. Porto Alegre: Sulina, 2012. Série Imagem-Tempo. 231p.

NOME. Arnaldo Antunes et al. SONY BMG MUSIC. São Paulo/Rio de Janeiro: 2005. CD e DVD.

PENN, Gemma. Análise semiótica de imagens paradas. In: BAUER, Martin W.; GASKELL, George (Org.).Pesquisa qualitativ com texto, imagem e som. Petropólis, RJ: Vozes, 2012. Cap. 13, p. 319-342.

ROSE, Diana. Análise de imagens em movimento. In: BAUER Martin W.; GASKELL, George (Org.).Pesquisa qualitativa com texto, imagem e som. Petropólis, RJ: Vozes, 2012. Cap. 14, p. $343-364$

SANTAELLA, Lucia. Matrizes da Linguagem e Pensamento sonora, visual e verbal: aplicações na hipermídia. São Paulo: lluminuras, FAPESP, 2005. 